\title{
Sección temática Elecciones 2017-2018 en América Latina ante el cambio de ciclo político
}

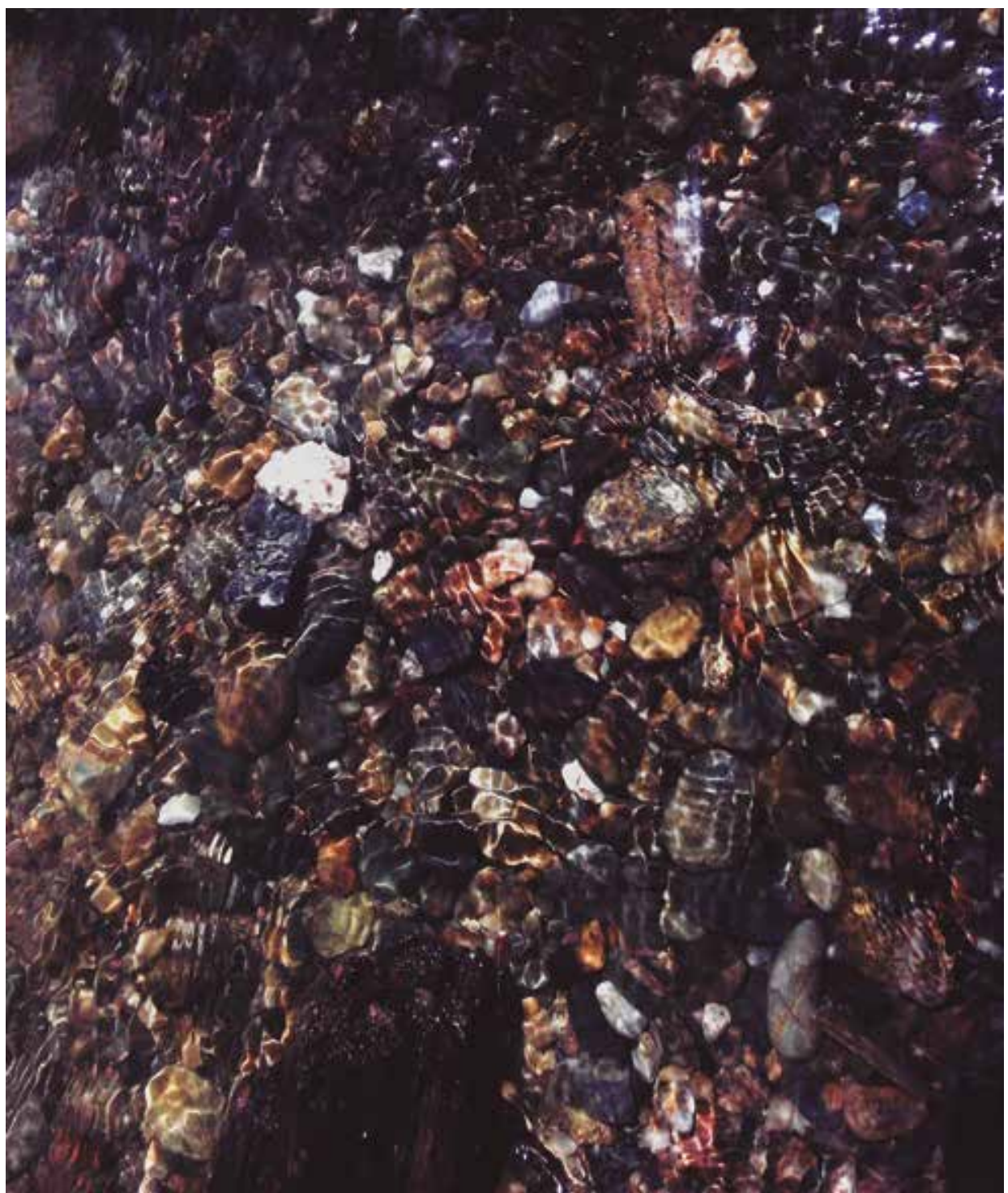

Sin título

De la serie Ungidos (o como derivar entre las rutas del agua)

Fotografía digital

2018

Medellín 


\section{Presentación. Elecciones 2017-2018 en América Latina ante el cambio de ciclo político}

Esta edición de la revista Estudios Políticos integra su sección temática con cuatro artículos que tratan sobre las elecciones presidenciales en Honduras, Chile, Paraguay y México, todas ellas acaecidas entre 2017 y 2018. En general, los artículos ofrecen un panorama de la disputa por el poder presidencial e informan, con algún nivel de detalle, los factores que marcaron cada coyuntura electoral. De este modo, aportan pistas para entender los resultados y su vínculo con la historia electoral reciente de cada uno de estos países.

Cecilia Graciela Rodríguez propone en Elecciones bajo sospecha. Análisis de las elecciones generales en Honduras 2017 asociar los resultados de los comicios con los cambios en el sistema bipartidista que se vienen fraguando en la última década. Estos cambios no solo atañen al Ejecutivo, sino que han modificado el equilibrio de las fuerzas políticas con presencia en el Legislativo hondureño. Adicionalmente, resalta las dificultades en el reconocimiento pleno de los resultados de las elecciones presidenciales, tanto por los problemas de gestión del Tribunal Supremo Electoral como por las tensiones alrededor de la reelección presidencial que han acompañado el debate electoral desde 2013 y las sospechas de fraude en los comicios.

Por su parte, Facundo Cruz y Carlos Varetto en Crónica de un cambio anunciado. Las elecciones de 2017 en Chile frente al cambio de sistema electoral muestran los ajustes en la oferta de actores partidarios y en el reacomodo de los subsistemas presidencial y legislativo en la democracia chilena. Argumentan que los resultados de las elecciones de 2017 se enmarcan en una tercera etapa de la evolución del sistema de partidos, en la que los niveles de fragmentación y volatilidad de los subsistemas presidencial y legislativo empiezan a confluir, confiriendo mayor importancia a la negociación entre los actores partidarios para el desempeño del gobierno y su esfuerzo por gestionar una agenda política propia.

En el tercer artículo de la sección, Fricción, (re)concentración y afianzamiento conservador tras las elecciones de 2018 en Paraguay, Juan Mario Solís y Sarah Patricia Cerna plantean la siguiente paradoja: unos resultados favorables a la consolidación del Partido Colorado en las diversas instancias de poder están acompañados por el riesgo de inestabilidad en el ejercicio de gobierno, derivado de las tensiones entre los líderes y las facciones más 
poderosas del partido mayoritario. A este planteamiento se agrega una descripción de los resultados electorales en los que se muestra que las fuerzas más conservadoras mantienen copado el escenario de representación, lo que hace inverosímil el avance de una agenda legislativa progresista, manteniendo el régimen político alineado en el ala más conservadora de la política latinoamericana.

En el cuarto y último artículo de la sección, Jaime Aragón, Alfredo Fernández y Juan Bautista Lucca analizan Las elecciones de 2018 en México y el triunfo del Movimiento de Regeneración Nacional (Morena). Con este propósito plantean un esquema en el que hacen una revisión del sistema de partidos mexicano, reconstruyen la génesis de Morena asociada con la trayectoria política de Andrés Manuel López Obrador y, a partir del escrutinio de los resultados electorales, postulan la idea de que, bajo estas condiciones, se inaugura en México un nuevo sistema de partidos.

Vistos en conjunto, los artículos registran, de un lado, los cambios en la orientación política en México y Chile y, de otro, la conservación del poder por parte de las redes políticas establecidas en los casos de Honduras y Paraguay. Igualmente, la aproximación a los casos pone en evidencia el impacto en los cambios de las reglas de juego - por ejemplo, en la conformación del Legislativo chileno - o de la discusión en torno a la estabilidad de estas por ejemplo, a propósito de las tensiones alrededor de la reelección tanto en Honduras como en Paraguay- Con esto se subraya la delicada línea que mantiene la confianza en las instituciones electorales, lo que resulta vital para la preservación de la democracia. Por último, el contenido de la sección temática aporta elementos sobre los cambios en la oferta partidaria, con reconfiguraciones del sistema de partidos en algunos de sus niveles y modificaciones en el equilibrio de poder entre los presidentes y las fuerzas legislativas, todo ello con un impacto significativo en la gestión gubernamental, sobre todo en los casos de Chile, Paraguay y Honduras.

Finalmente, este ciclo electoral en América Latina —que aún no concluye - ha tenido curso en un contexto marcado por el incremento de las denuncias de prácticas de corrupción o de mala gestión gubernamental, situaciones que alimentan la percepción de muchos ciudadanos de que los políticos persiguen prioritariamente sus propios intereses y que poco se esfuerzan por articular adecuadamente el destino de la nación y de los ciudadanos con la gestión política de la sociedad. 
Todo esto se expresa en un incremento en los niveles de desafección frente a las instituciones de las democracias liberales de la región, lo que alimenta la desconfianza en la regulación democrática de la política y se refuerza con otra serie de fenómenos como el peso creciente de los medios de comunicación y de la redes sociales, los giros que ha tomado recientemente la personalización de la política, la relevancia del espectáculo y los escándalos alrededor de la vida privada y pública de los políticos, con la generalización de unas prácticas en las que se intenta proteger desesperadamente la propia reputación, al tiempo que ayuda o tolera el daño en la imagen del contendor, con un efecto de deterioro acumulativo de la credibilidad de la institucionalidad democrática en su conjunto. Resulta vital un análisis más agudo que permita vincular este contexto general con los desenlaces de la competencia en las urnas, para vislumbrar cuál es el signo específico de los riesgos que corre la democracia en América Latina.

\author{
Manuel Alcántara Saez (España)* \\ Juan Carlos Arenas Gómez (Colombia) ${ }^{* *}$
}

\footnotetext{
* Editor invitado revista Estudios Políticos. Licenciado en Ciencias Políticas y Sociología. Doctor en Ciencias Políticas. Catedrático del Área de Ciencia Política y de la Administración, Universidad de Salamanca, España. Correo electrónico: malcanta@usal.es - Orcid: https://orcid.org/0000-00016483-3165

${ }^{*}$ Editor invitado revista Estudios Políticos. Sociólogo. Magíster en Ciencia Política. Grupo Estudios Políticos, Instituto de Estudios Políticos, Universidad de Antioquia UdeA. Calle 70 No. 52-21, Medellín, Colombia. Correo electrónico: juan.arenas@udea.edu.co

Cómo citar este artículo: Alcántara Saez, Manuel y Arenas Gómez, Juan Carlos. (2019). Presentación sección temática. Elecciones 2017-2018 en América Latina ante el cambio de ciclo político. Estudios Políticos, 54. pp. 200-202. http://doi.org/10.17533/udea.espo.n54a10
} 